\title{
Integrating Social Mapping with Geographic Information Systems: Community Network Analysis in Sharing Sweetpotato Innovations in Papua New Guinea
}

\author{
Lilly Pasa Sar ${ }^{1}$, Anton Mais ${ }^{2}$, Isidora Ramita ${ }^{2}$, Amanda Wandau², Cathy Koloa ${ }^{3}$, Barton Maino Gabi ${ }^{3}$ and Lucy \\ Maino $^{3}$ \\ 1. Centre for Social and Creative Media, University of Goroka, Goroka 441, Papua New Guinea \\ 2. Papua New Guinea National Agricultural Research Institute, Lae 411, Papua New Guinea \\ 3. Department of Communication for Development Studies, Papua New Guinea University of Technology, Lae 411, Papua New Guinea
}

\begin{abstract}
This research drew from social learning and international development literature. The purpose of this community research was to trace the spread and impact of sweetpotato flour in two rural communities in Papua New Guinea. Research strategy was participatory learning and action utilizing participatory mapping. The paper mapping process was documented using a video recorder and field notes. Geographic Information Systems technology was then used to incorporate local spatial knowledge on scale maps to show spread of knowledge. The main finding was the identification of social networks through tracking of sweetpotato knowledge: identifying who used the knowledge and whether there were any modifications, the location of those who used the knowledge and whether this was shared and with whom. Most significant was the enabling factors that strengthened existing and potential future networks. Community leadership styles determine success of development projects. Rural communities are diverse needing participatory multi-layered methodologies that are people oriented for agricultural technologies to be learnt and utilized for improved livelihood.
\end{abstract}

Key words: Social mapping, social learning, agricultural innovation, sweetpotato, Papua New Guinea.

\section{Introduction}

Early development models used communication to disseminate information so that people could understand the 'benefits' promised through research interventions. This was based on the assumption that when wealth was acquired, this would then automatically filter down to all levels of the community; including top to bottom communication practices. Rogers, E. M. [1] work on 'Diffusion of Innovations' has been very influential in this area. He identified four elements for diffusion of innovation to be adopted which are the innovation, the communication channels, the time and the social system. Diffusion is the process by which an

Corresponding author: Lilly Pasa Sar, Ph.D., research field: communication for social change. innovation is communicated through certain channels over time among members of a social system. The five stages of innovation include awareness, interest, evaluation, trial and adoption. Adoption is the process used by individuals to arrive at the decision to reject or accept the innovation from the time it is first introduced.

However, despite the assumption that innovation would eventually diffuse through the community, this did not have the expected impact hence a lot more is needed to be done to have the intended effects [2]. The linear model of innovation where scientists develop an innovation, disseminated through the conventional extension systems and then put into practice by end users has been criticized [3] noting that communities are far too complex needing more than a linear process. 

Analysis in Sharing Sweetpotato Innovations in Papua New Guinea

Communication in innovation has progressed from the top down linear process to engaging people in their own development using participatory approaches. PRA (Participatory Rural Appraisal) methods engage people and locate agriculture as one of the contributing factors in people's livelihoods [4]. This method is a 'bottom-up' approach [5] where research begins with the people in the community and focuses on facilitating farmers to be creative in gathering and analyzing data on issues that affect them. The PRA method does not only facilitate 'participation' but also encourages changes in approaches taken by development agencies.

In PRA methods, a widely used tool has been in mapping in farmer participatory research. Although mapping activities are participatory, care needs to be taken in facilitating the process. Facilitator decides in consultation with the participants whether map is drawn on the ground first, then transferred to paper or to use with PGIS (Participatory Geographic Information Systems). The style and mode of facilitation can affect nature of power relationships.

Ground and paper maps can have multiple applications and uses; a few to mention would be Natural Resource Mapping, Participatory Monitoring \& Evaluation - to impact monitoring of soil and water conservation and changes in farming practices. Other uses include social mapping - to identify households, people, livestock and people in other social categories. This paper used social mapping for tracking and locating sweetpotato (Ipomoea batatas) knowledge in communities.

When people are allowed to make their own maps using local spatial knowledge, they can plot points of interest with much excitement, cross-checking and correction. People enjoy drawing maps and bring so much satisfaction when they see their spatial realities in a new way as reflected in this study. A rural smallholder farmer in PNG (Papua New Guinea) explained “...I thought I wasn't going to make a map, I thought I will just go and observe, I am very happy, we were able to draw a map."

Discussion over the map has advantages over purely verbal discussion. Map is a visual agenda with local detail and spatial relationships shown and can be seen all at once. When people point, touch or feel the map, this leads to forming rich insights.

A relevant field for communication in the innovation process is the literature from social learning which recognizes that learning occurs across the hierarchy from farmers to organizations. According to Woodhill, J. and Röling, N. [6], it is a participatory process enabling social change which is based on:

- Critical self-reflection;

- The development of participatory multi-layered democratic process;

- The reflexive capabilities of human individuals and societies;

- The capacity for social movements to change political and economic frameworks for the better.

Learning from this point of view focuses on human actor [6] and refers to how people's experience in interaction with their environment affects their past perceptions which are then linked to decisions for their future. Therefore, it is important to engage people using their IK (Indigenous Knowledge), a crucial enabling factor in learning introduced knowledge. However, in PNG, the use of IK has not been developed further than just proposals made to take into account the 'cultural context' of the people. Acknowledging the importance of local knowledge recognizes the extreme diversity of rural communities, their priorities and perceived needs.

The purpose of this research was to gain insight into how people shared the newly acquired knowledge on sweetpotato processing technology. The intention was to map out the spread and location of sweetpotato knowledge in the selected village communities through understanding the sharing habits of farmers of the recipes and products of sweetpotato flour. Exploring the sharing habits of people allowed them 
to give their perspective on the project and allowed the project team to also become aware of established community social networks.

\section{Research Strategies}

This research was based on a part of a larger project 'Market Diversification and Sweetpotato Processing in Papua New Guinea'. Project was a partnership between the PNG NARI (National Agricultural Research Institute) and ACIAR (Australian Centre for International Agricultural Research). Training was provided on sweetpotato processing and value adding. Sweetpotato flour processed in NARI research centre was distributed in selected communities in PNG. Participating communities were also encouraged to process their own sweetpotato flour after trainings were conducted.

\subsection{Participating Communities}

Participants engaged were from two LLG (Local Level Government) communities-Erap-Wain and Wampar in Morobe Province PNG. The first group comprised smallholder farmers who were members of the Kasuka Cooperative Society from the middle Erap LLG. The cooperative comprised of 7 villages: Kwerebo, Kawalang, Barawang, Bayang, Sibi, Sawana and Kwaleng with a population of approximately 5,000 people.

The second group was smallholder farmers from Gabensis village, Wampar LLG with a population of approximately 7,000 people. This is a large village community compared to most villages in PNG.

\subsection{Participatory Process}

The participants from the two different communities were seen at different times. Therefore, the maps for middle Erap community and Gabensis were developed independently. Each community was visited twice with the second trip to review the map and to cross-check for accuracy. Digital copies of the ground and paper maps together with the GIS maps were put in photograph albums and left in the communities as community resources. These maps could be used as resource materials by the communities in future development interventions.

Information on recipe development and modification was also collected through matrix. This was done in one community only where participants were actively developing recipes and has shared the information widely.

\subsection{Documentation}

Video camera was used to record both the conversations when maps were developed and as well as the subsequent activity-discussions generated around the maps was documented. Documenting the exercise was essential to learn from farmers their knowledge and experiences in utilizing the sweetpotato flour. The recorded material could also be useful for long term archiving of local knowledge, thus may have uses beyond this study. This includes evaluation stage of the project and when communicating the project's progress to project partners including funding agencies.

\section{Results}

\subsection{Community Social Maps}

The mapping process was completed in 2 communities.

\subsubsection{Community 1: Erap-Wain Community}

The community social mapping was done in Sibi village at the community resource centre. In the first visit, there were a total of 30 participants while the second visit had 15 participants. Participants were informed that they were to do two maps: a whole community map and Sibi village map. Sibi village had a separate map as this village is the central location where $\mathrm{R} \& \mathrm{D}$ organizations (Research and Development) met and interacted with the people. Participants formed two groups: one group completed map of Sibi village and the other group mapped the whole community including Sibi village (Fig. 1). 
Participants were encouraged to use locally available material in addition to stationery from shops such as colored papers and sticky tapes. The community social map was drawn beginning with the location of the resource centre and then the main road, the mountains, the rivers and other relevant topographic features of the project sites.

The team working on the community map (Fig. 1A) identified all villages from which people participated in the project. Information on the map also included households where sweetpotato flour knowledge was utilized, number of households and the location of drum ovens used for baking sweetpotato flour products. Features included location of community resources such as schools, health clinics, churches and development interventions such as fish ponds for aquaculture, rice (Oryza sataiva) and pineapple (Ananas comosus) fields.

Cash crops such as coffee (Coffea arabica) and cocoa (Theobroma cacao) were widespread, so the team did not include those cash crops on the map. The only drum oven in the community was located in Sibi village and owned by a community leader. Drum ovens were essential to people experimenting with the different recipes developed.

Out of the initial 7 villages identified as project villages, only participants from Sibi village were actively utilizing the sweetpotato flour in developing new products. Sibi village map (Fig. 1B) had details on location of households who had attended postharvest training, those who attended training and actively using the skills learnt, those who attended the training and shared the skills sweetpotato knowledge and those who did not attend training but learnt the skills from others.

Beside each household using the sweetpotato flour, participants also showed types of recipes cooked. There were a total number of 16 households using the flour and from the map, substantial number of recipes developed. Cooking was done in a cooking group, mostly women members.
Sibi participants modified their recipe 6 times on average. Information on dominant food crops was also included on the map showing Chinese taro (Xanthosoma sagittifolium) as major food crop.

As in most rural communities in PNG, distance from the urban centre contributes to lack of access to the markets. There is no rural electricity service although there were a few households using generators and solar equipment to provide light.

A major enabling factor in the middle Erap villages was the presence of a champion, VSO (Volunteer Service Officer) Priscilla Lilih, employed to facilitate development interventions in the community. The central point of meeting for R \& D organizations was in Sibi village. The VSO role ensured the community benefited from the various projects by organizations and worked very closely with the community leaders and also kept in touch with the R \& D organizations. Over time, the VSO volunteer had developed rapport with community leaders and established a system of coordinating information and networked with outside organizations.

Some R \& D organizations present in the community were NARI (Inland Aquaculture, Rice and Sweetpotato Postharvest), Trukai (Rice), Faith based organizations (Promoting Healthy Island concept), FPDA (Fresh Produce Development Agency) involved with fresh products, other $\mathrm{R} \& \mathrm{D}$ organizations (Cash crops - coffee and cocoa). The community had also linked with urban supermarkets selling fresh vegetables. The Evangelical Lutheran Church was also a major contributor to improving livelihood.

\subsubsection{Community 2: Gabensis Village}

In Gabensis village, maps were first done on the ground, and then participants transferred the maps to large sheets of papers. On the maps, participants located those who attended training in food processing, those who proceeded to cooking recipes, who shared the knowledge on sweetpotato recipes and with whom they shared. 

Analysis in Sharing Sweetpotato Innovations in Papua New Guinea

Gabensis village is very well structured into 8 sections (Fig. 2) with nominated leaders coordinating development activities. The leaders in each section worked with the overall village committee chairperson.

There was plenty of potential for more households to use sweetpotato flour from interest shown by women living towards the centre of the village where most people lived. There were three drum ovens in the village and one of these was owned by the community project coordinator Sam Ifid. Sam Ifid also managed a village based Agro tourism eco-lodge.

The population in Gabensis village alone is higher compared to the 7 villages put together in the Wain Erap community. Therefore, if sweetpotato flour innovation was successful in this village, the impacts would be significant. However, sweetpotato flour was utilized by limited number of people in Gabensis. This may have been due to people buying sweetpotato from urban markets to process into sweet potato flour. Banana (Musa spps) is the staple crop and sweetpotato is not grown. Therefore, sweetpotato had to be purchased in urban markets for processing and developing recipes.

Gabensis farmers used kinship networks for sharing the sweetpotato flour knowledge. The demand for external knowledge was high, but due to limited access to external knowledge and information, local systems have developed to utilize their own networks such as family, friends or neighbors through which information is exchanged. Therefore, the style and mode of sharing and exchanging information on development interventions depend on knowing and understanding the behavior of these networks [7].

The leader of the Agro tourism eco-lodge Sam Ifid is an overall village leader whose role extended from managing information between the village and $\mathrm{R} \& \mathrm{D}$ organizations. Sam Ifid's role was to coordinate activities with other village leaders, efficient resource management and maintain harmony while linking with outside organizations. This village had access to electricity but only those who could afford the costs had connections to their homes. Gabensis village had cocoa cooperative and had a strong presence of the Niugini Table Bird Poultry as most households were engaged in raising chickens, which were then sold back to the industry.

3.1.3 Sweetpotato Product Development in the Two Communities

In addition to gathering information on sweetpotato flour utilization, information was also gathered on product developed using matrix to show how recipes were modified.

Sibi village had 16 households participating. Products developed were doughnut, pastry with pumpkin (Cucurbita moschata) and Irish potato (Solanum tuberosum), scone, fried flour, sweetpotato cookies, banana cake, peanut (Arachys hypogea) cookies, Ukoi-pumpkin (Cucurbita moschata), pawpaw (Carica papaya), strawberry (Fragaria spp) flavoured cookies, steamed banana cake, bun, bread, cassava (Manihot esculenta) doughnut with locally made desiccated coconut, pizza, bun—various flavors. The products were modified on average 6 times.

Gabensis village had 7 households who participated actively in product development which ranged from sweetpotato strips, cassava sweetpotato cake, fried sweetpotato balls, sweetpotato sago (Metroxylon sagu) fried, doughnut, cookies (pumpkin, banana), boiled sweetpotato flour, fried sweetpotato flour \& rice balls.

Participants in Gabensis did not modify as much as the Sibi participants, modifying products only twice on average. There were two types of modification done to the original recipes. The first was adjustments done to the ratio of the composite flour and wheat flour to improve dough from being either too soggy or too stiff to dough to their satisfaction. The second modification was to add flavor by adding food coloring, locally available fruits and vegetables.

Farmers expressed concerns over the cost of ingredients and had decided to use more local ingredients which encouraged creativity. A major cost 


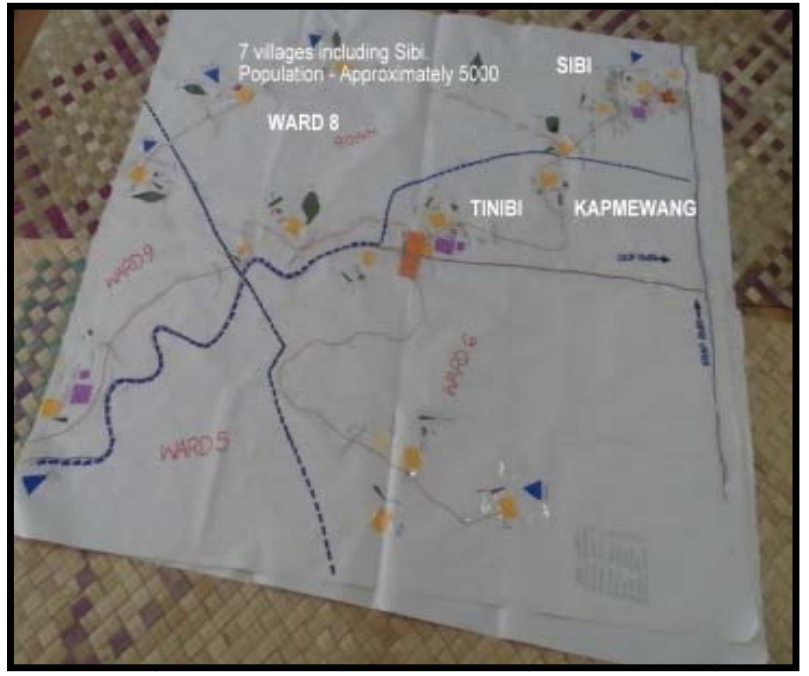

(a)

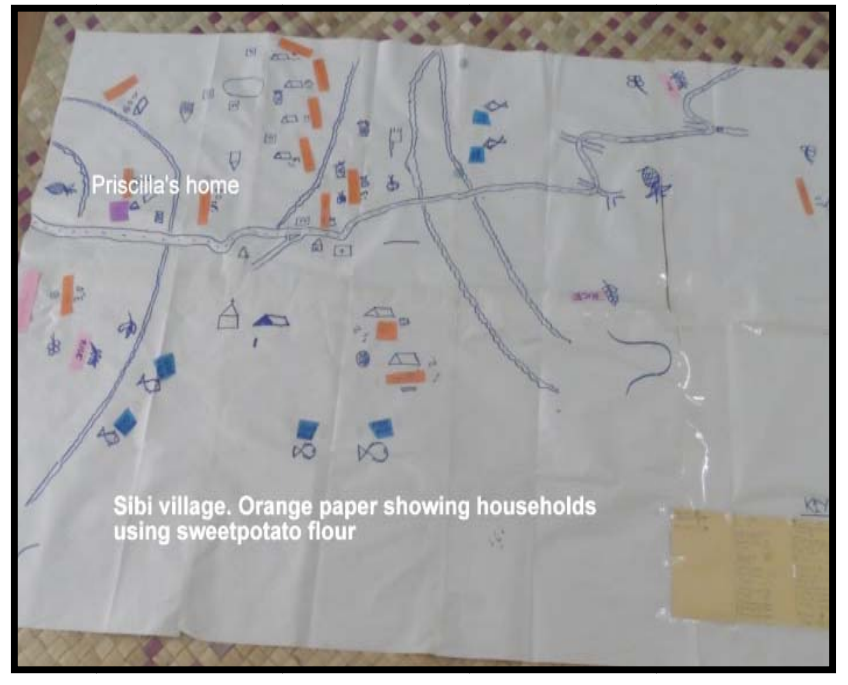

(b)

Fig. 1 Erap-Wain community maps.

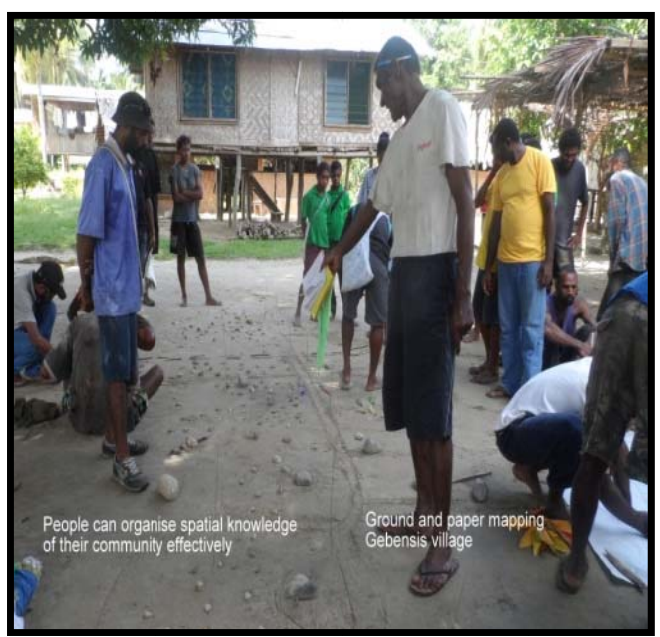

Fig. 2 Gabensis community social maps.

was buying sweetpotato to produce the composite flour locally. Most participants in Gabensis village bought sweetpotato as this was not widely grown in this community although farmers have begun cultivating this crop. Erap-Wain villages have Chinese taro as their dominant crop while Gabensis is a banana farming system. Other concerns were over appropriate equipment for processing of sweetpotato flour at the community level.

\subsection{Integration of Social Mapping with GIS Technologies}

GIS technology was introduced only when data on ground and paper maps were crosschecked and people had indicated points of interest and relevant information on sweetpotato flour utilization and their community development. This was to ensure social inclusion in learning farmers' experiences before introducing the GIS technology.

Reason for the integration of social and GIS mapping was to integrate local spatial knowledge using technology and to show the spread of knowledge using buffer zones. Paper maps were useful in locating sweetpotato knowledge in participating communities. GIS maps also allowed for sharing of community information with R \& D organizations and donor agents. 

Analysis in Sharing Sweetpotato Innovations in Papua New Guinea

\subsubsection{Erap-Wain Social and GIS Maps}

In Sibi village, a GPS (Global Position System) waypoint of the main or central point in which sweetpotato flour was first introduced was taken. This was at the community resource centre. GPS waypoints of participants of the sweetpotato processing training and who were actively using the flour were also taken. Waypoints were gathered in participating villages.

Sweetpotato flour was also shared from Tinibi village to Rabisap village. GPS waypoint of Rabisap was not taken due to inaccessibility by road (Fig. 3). An existing census unit point data layer in the NARI cultural database which showed Rabisap village was used instead. Existing road layer also from the NARI cultural database was also used. GPS waypoints were then imported into open source GIS software, QGIS 1.8.0-Lisboa. Descriptions pertaining to respective points were entered and individual shape file layers were created based on the purpose of the map. Using the plug-in MMQGIS in the QGIS 1.8.0-Lisboa, three network systems were created. But due to loss of original soft copies of waypoints and with only hard copy of the map initially created by QGIS 1.8.0-Lisboa, the map was georeferenced using road network to re-create the three network systems (Fig. 3) using QGIS 2.14.8-Essen.

The first was the network from Sibi village to other villages. The VSO volunteer's house was the hub and spokes from her house connected to Guruge Timoti's house (Sabang village), Roselyn Gisang's house (after Kapmewang village), and Melba Ginigin's house (Tinibi primary school). Guruge, Roselyn and Melba are active participants in developing and trialing sweetpotato products. The second network was the further spread from Melba Ginigin’s house to Rabisap village where her sister was also utilizing the sweetpotato flour.

Four buffers were also re-created by georeferencing the original map using QGIS 2.14.8-Essen. These buffers depict the possible spread of sweetpotato knowledge. The buffer around Priscilla's house and
Sibi resource centre spanned $600 \mathrm{~m}$ while, Melba Ginigin at Tinibi school had a buffer of $400 \mathrm{~m}$ and Guruge Timoti and Roselyn Gisang $200 \mathrm{~m}$, respectively. Other points of interest that were marked with the GPS were also included such as the ADRA (Adventist Development and Relief Agency) Healthy Island Concept.

The third network was within Sibi village as well as other important points identified by the farmers such as the location of ovens, fruit trees and gardens, water sources, aid post, canteens and other points of interest that were captured in the GPS. The GPS point of Priscilla Lilih's house was the hub and homes in the cooking group actively using sweetpotato flour had spokes connecting to their GPS locations. The sweetpotato flour was processed and recipes developed more in Sibi village than the other villages in the Erap-Wain communities.

3.2.2 Gabensis Social Mapping Integration with GIS Maps

In Gabensis village, the same method was employed as Erap-Wain community re-mapping process by georeferencing the original map using QGIS 2.14.8-Essen. A GPS waypoint of the central point where sweetpotato flour knowledge was first introduced was taken. This was the home of the manager of the eco-lodge, Sam Ifid. GPS waypoints of homes that were given sweetpotato flour were also taken. From these GPS points, a network map showing Sam Ifid's house as the hub and spokes connected from it to the other homes that were given sweetpotato flour.

On Gabensis map, a buffer of $400 \mathrm{~m}$ showing possible spread of sweetpotato flour knowledge was created around Sam Ifid's house (Fig. 4).

A second buffer of $300 \mathrm{~m}$ was created around the Gabensis primary school. The school teachers were very keen in developing sweetpotato products and these were sold within the school. Other significant points such as the location of ovens, churches and schools were taken and included in the map as well. 

Analysis in Sharing Sweetpotato Innovations in Papua New Guinea

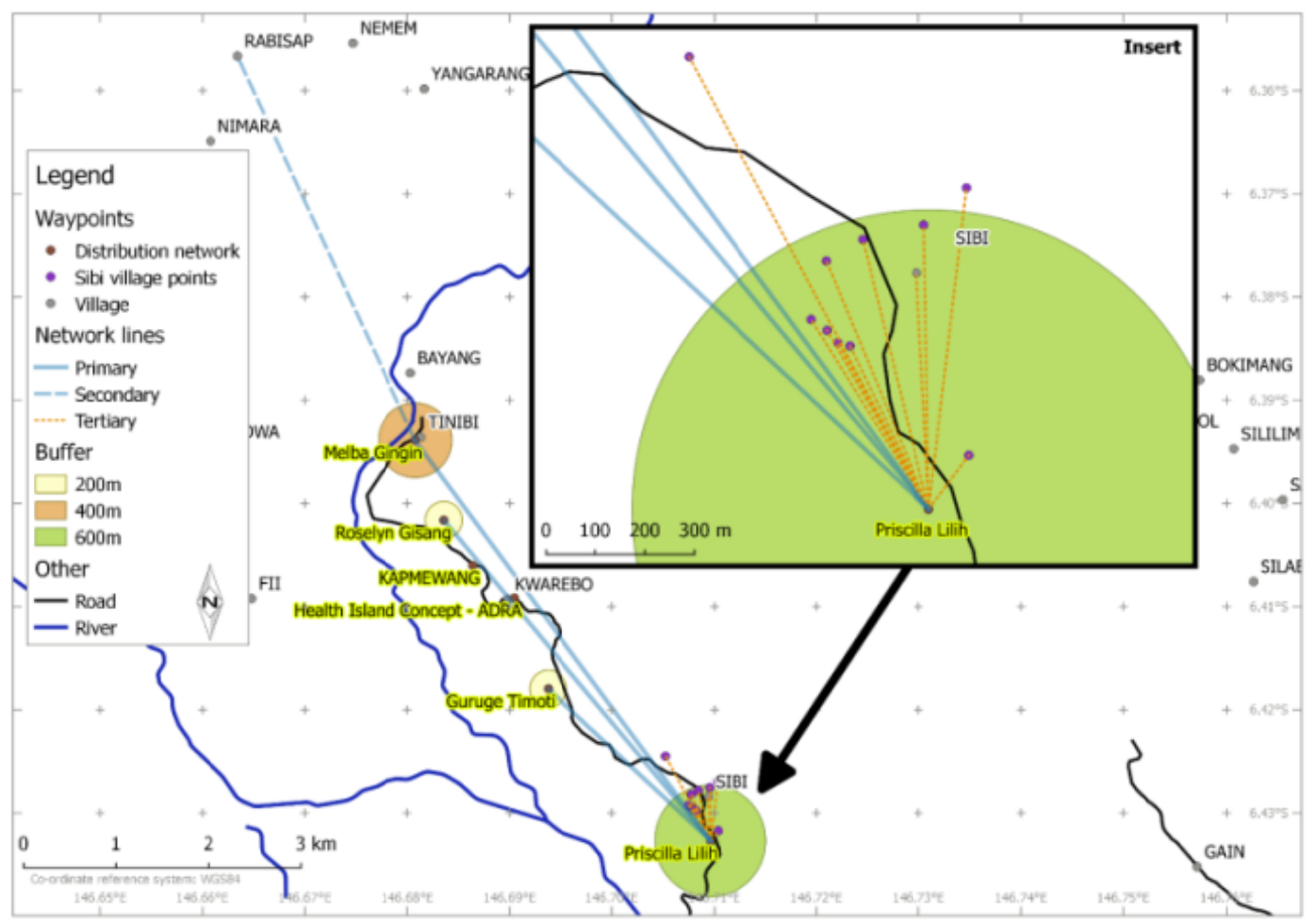

Fig. 3 Erap-Wain sweetpotato flour networks.

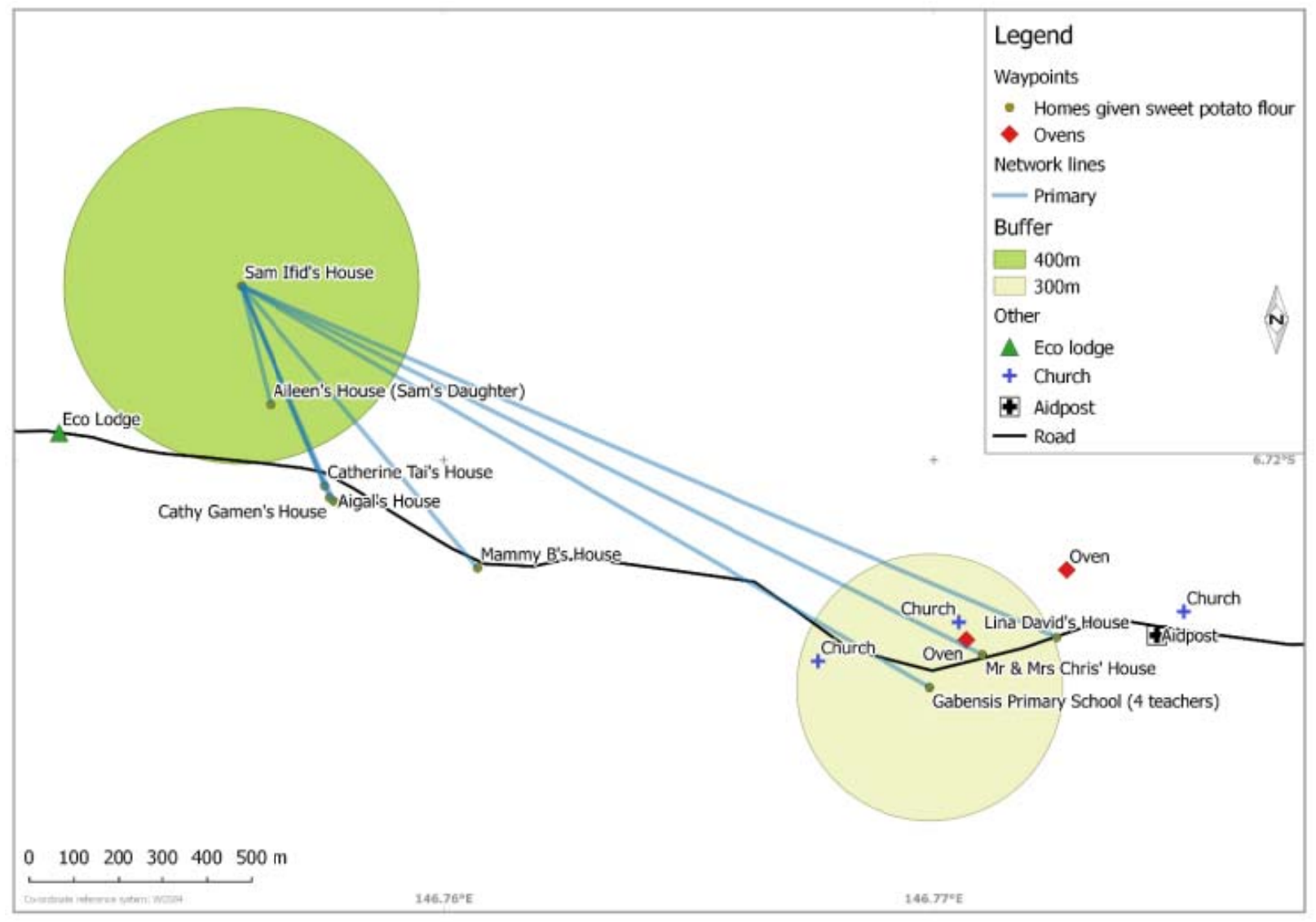

Fig. 4 Gabensis village sweetpotato flour networks. 


\section{Discussion}

\subsection{Community Networks of Postharvest Technologies}

Over time, non-adoption by farmers has been attributed to their ignorance and to imperfect communication. The blame is not on technology but a failure on communication, top-down and one-way process from scientists to farmers. In this case, adoption is centralized, standardized and simple; Top-down knowledge, generated, transferred and packaged for adoption. However, TOT (Transfer of Technology) is increasingly questioned as it does not work well with more complex, diverse and risk-prone communities, particularly that of PNG rural communities. There is a need to develop participatory multi-layered democratic process [6] to engage all stakeholders including the rural smallholder farmers. Wider choices of information sources are needed to allow farmers to make informed livelihood decisions. In order to address diverse information needs in communities, a pluralistic approach, necessary to enable a wide range of flexible methodologies for sharing and exchanging information is needed. Adapting methodologies through which people can choose relevant information is a greater force for change in their own lives.

Data from the social maps showed community kinship networks [7] of the sweetpotato postharvest technology. The social networks in the Erap-Wain communities were typical of sharing and exchanging behaviour due to the presence of the champion. However, there are many other contexts where behaviour is not a result of control from a central authority common in the TOT approaches.

A shift in mindset that recognizes networks of self-organization has been gradual in PNG NARS (National Agricultural and Research System). Self-organizing systems [3] recognize complex and dynamic community issues affecting development and use bottom-up approaches.

Use of participatory and multiple methodologies [6] using bottom-up logic and emphasis is on principles and values guiding decision making and not just following rules and conventions rigidly. Therefore, a practical application of self-organized systems is through using PRA and other participatory approaches. Participants are encouraged to use judgement based on principles and values, to choose and interpret what to do. The notion is not to give a recipe or instructions on how to but ingredients or set of tools from which to select and what to use to make a recipe of their choice. The sweetpotato project is a good example where processed sweetpotato flour was given out and participants had to choose their own ingredients and develop sweetpotato products.

In order for sustainable agricultural development, appropriate methodologies together with the presence of local champions in communities create an enabling environment. This approach requires development agents to know community, to listen first before telling people about an innovation [4]. In doing so, relationships are built and leadership established. Local leaders continue to engage communities, long after projects end, so impacts of development interventions can be achieved over time.

\subsection{Leadership within Community Structures}

Sibi village had actively engaged in developing sweetpotato products and spread of information in households was better than in Gabensis village. A major contributing factor to this was the type of project leadership in community. Sibi community was successful in learning and sharing information due to the presence of the central leader on agricultural projects who facilitated learning of new information. Gabensis leadership was different as the leader of the project was overall community leader who had to oversee general development of the village.

Rogers, E. M. [1] recognized the social structure as one of the contributing factors in learning innovations. In PNG, diffusion and adaptation processes are embedded in the social system of a community. 
Therefore, people adopt new information or innovation depending on the relationships between and within the social system.

\subsection{Scaling up and out: Market Diversification of} Sweetpotato Technologies

The networks in the communities showed the potential links to increase demand for the sweetpotato products. Current network analysis showed necessary relationships in place to show project outputs. These networks could then be used to identify potential future networks both within and outside the community to diversify market for sweetpotato products and develop new sweetpotato value chains. Participatory approaches in engaging smallholder farmers inherently have the advantages of scaling-up and scaling-out the postharvest technologies. Networks could be strengthened with farmer organizations, NGOs (Non-Government Organisations), R \& D and LLG and private service providers could work in collaboration. This type of network building recognizes learning across organizations [6] and the use of multiple methods for social change.

\section{Conclusions}

Some lessons learnt for rethinking communication in the innovation process are identified as network building, social learning as a process for learning introduced innovation, understanding community into which the technology is to be introduced and to also plan scaling processes at the planning phase of the project.

It is also necessary to pay attention to network building and the enabling forces for research interventions to impact and bring social change in rural communities. Power structures in communities also determine the strength of relationships that make up networks and also influence how information is exchanged. There are circumstances where certain technologies may not be shared widely except in closed networks as in kinship networks as observed in this study. In order to address such complexities, methodologies are needed to look beyond the linear, control oriented top-down concept that often misses out on showing realities that are obscured or misperceived. Social learning is considered to be a crucial process for developing a conducive fit between the innovations and their environments.

There is also a need to understand community dynamics and power issues to overcome resistance in a very productive way. Change agents in the innovation process need to break out of the frequently used purposes of persuasion or advisory role to engage people from the planning phase of development interventions. This study has shown genuine engagement will require appropriate methodologies, knowing community leadership structures and understanding the social context. Future studies should look further into exploring how community networks could be utilised in scaling up and scaling out processes to ensure intended benefit has the needed impact.

\section{Acknowledgements}

Thanks to Dr. Christie Chang-University of New England, Armidale, Australia and Dr. Donald Irving - New South Wales Department of Primary Industry, Australia.

\section{References}

[1] Rogers, E. M. 1995. Diffusion of Innovations. New York: Free Press.

[2] Chambers, R. 1992. "Rural Appraisal: Rapid.” Relaxed and Participatory 311.

[3] Röling, N. 1988. Extension Science: Information Systems in Agricultural Development. Cambridge: Cambridge University Press.

[4] Quarry, W., and Ramírez, R. 2013. Communication for Another Development: Listening before Telling. London: Zed Books.

[5] Chambers, R. 2008. Revolutions in Development Enquiry. London: Earthscan.

[6] Woodhill, J., and Röling, N. 1998. "The Second Wing of the Eagle: The Human Dimension in Learning Our Way 
Integrating Social Mapping with Geographic Information Systems: Community Network Analysis in Sharing Sweetpotato Innovations in Papua New Guinea

to More Sustainable Futures.” Facilitating Sustainable Agriculture. Participatory Learning and Adaptive Management in Times of Environmental Uncertainty 46-71.
[7] Sar, L. P. 2010. "Communication about Communication: The Use of Rural People's Knowledge.” Unpublished Ph.D. dissertation, School of Natural and Rural Systems Management, University of Queensland, Australia. 